\title{
The old and new tests for celiac disease: which is the best test combination to diagnose celiac disease in pediatric patients?
}

\author{
Ignazio Brusca ${ }^{1} *$, Antonio Carroccio ${ }^{2}$, Elio Tonutti ${ }^{3}$, \\ Danilo Villalta ${ }^{4}$, Renato Tozzoli ${ }^{5}$, Maria Barrale ${ }^{1}$, \\ Filippo M. Sarullo', Pasquale Mansueto', \\ Stella Maria La Chiusa ${ }^{1}$, Giuseppe Iacono $^{7}$ and \\ Nicola Bizzaro 8 \\ ${ }^{1}$ Department of Clinical Pathology "Buccheri La Ferla", \\ Hospital, Palermo, Italy \\ ${ }^{2}$ Internal Medicine, Ospedali Civili Riuniti, Sciacca, Italy \\ ${ }^{3}$ Immunopatologia e Allergologia, Azienda Ospedaliero- \\ Universitaria S. Maria della Misericordia, Udine, Italy \\ ${ }^{4}$ Allergologia e Immunologia Clinica, DML, AO Maria \\ degli Angeli, Pordenone, Italy \\ ${ }^{5}$ Laboratory of Clinical Pathology, AO Maria degli Angeli, \\ Pordenone, Italy \\ ${ }^{6}$ Internal Medicine, Department of Clinical Medicine and \\ Emerging Diseases, University of Palermo, Italy \\ 7 Pediatric Gastroenterology, "Di Cristina' Hospital, \\ Palermo, Italy \\ ${ }^{8}$ Laboratory of Clinical Pathology, Ospedale S. Antonio, \\ Tolmezzo, Italy
}

\begin{abstract}
Background: In the diagnosis of celiac disease (CD), serum assays for anti-endomysium (EMA) and anti-transglutaminase (anti-tTG) antibodies have excellent diagnostic accuracy. However, these assays are less sensitive in young pediatric patients. Recently, a new ELISA test using deamidated gliadin peptides (DGP) as antigen has proved to be very sensitive and specific even in pediatric patients. In addition, anti-actin IgA antibodies (AAA) is another test that can be used in $\mathrm{CD}$ patients because antibody concentrations correlate with the degree of villous atrophy. This study evaluated the clinical accuracy of anti-tTG, EMA, AGA, anti-DGP and AAA and the effectiveness of these in different combinations for diagnosing $\mathrm{CD}$ in a large cohort of pediatric patients.

Methods: Sera of 150 children under 6 years of age were tested: 95 patients had a diagnosis of $\mathrm{CD}$, while 55 patients who did not suffer from CD were used as controls. AntiDGP IgA/IgG and AAA were assayed with ELISA kits, while anti-tTG $\mathrm{IgA} / \mathrm{IgG}$ and $\mathrm{AGA} \mathrm{IgG} / \mathrm{IgA}$ were assayed using a quantitative fluoroimmunoassay. The EMA test was conducted by indirect immunofluorescence.
\end{abstract}

\footnotetext{
*Corresponding author: Dr. Ignazio Brusca, "Buccheri La Ferla" Hospital, via Messina Marine 197, 90100 Palermo, Italy

Phone: +39 091479271, Fax: +39091479268,

E-mail: ignbr@libero.it

Received April 4, 2011; accepted August 28, 2011
}

Results: Seventy-six of $95(80 \%)$ CD patients were positive for DGP IgA and/or tTG IgA. Eighty of 95 (84.2\%) patients were positive for DGP IgG and/or tTG IgA. None of the controls were positive for these antibodies. Eighty-four of 95 $(88.4 \%)$ patients and $8 / 55(14.5 \%)$ controls were positive for AAA and/or anti-tTG IgA.

Conclusions: In very young children, association of anti-tTG IgA with anti-DGP IgG is the best test combination for diagnosing CD, yielding a cumulative sensitivity of $84.2 \%$ and a specificity of $100 \%$.

Keywords: actin; celiac disease; children; diagnostic accuracy; endomysium; gliadin; transglutaminase.

\section{Introduction}

Celiac disease (CD) is an immune-mediated enteropathy triggered by gluten ingestion in genetically predisposed individuals. $\mathrm{CD}$ is one of the most common gastrointestinal disorders, with a prevalence of 1:100-1:200 in the general population (1-3). The large increase in $\mathrm{CD}$ diagnosis over recent decades is in large part due to the availability of immunoassays with excellent diagnostic accuracy, such as the IgA anti-transglutaminase (anti-tTG) antibody assay (4-8). However, discordant data between adults and children have been reported as the anti-tTG assay is less accurate in very young patients and autoantibody levels can fluctuate (9-11). In fact, the reported sensitivity for IgA anti-tTG, including all ages, ranges between $67 \%$ and $100 \%$, with a specificity between $96 \%$ and $100 \%(5,11-19)$, while in very young patients the sensitivity is lower, with a value ranging from $67 \%$ to $83 \%(11,17,18)$.

In addition to the anti-tTG assay, commercially available tests for $\mathrm{CD}$ diagnosis include IgA anti-endomysium antibodies (EMA) and IgA and IgG anti-gliadin antibodies (AGA).

EMA sensitivity in children ranges from $83 \%$ to $100 \%$ $(12,17,18,20)$, but is lower in children under 2 years of age, being approximately $85 \%(17,18,20)$.

AGA, in general, have lower diagnostic accuracy than anti-tTG and EMA, since these autoantibodies can also be detected in other enteropathies as well as in healthy individuals (21-25). In children, the sensitivity of IgA AGA ranges between $52 \%$ and $95 \%$ with a specificity between $68 \%$ and $98 \%$. IgG AGA have sensitivity similar to IgA AGA, but are affected by much lower specificity (approx. 50\%) (12, 20-29).

In 2005, the North American Society for Pediatric Gastroenterology, Hepatology and Nutrition (NASPHAGAN) 
issued a guideline for the diagnosis of pediatric CD (30). Although some pediatric $\mathrm{CD}$ patients may test negative for EMA and for anti-tTG and positive only for AGA (10, 31-33), the use of AGA was no longer recommended, because of its poor overall diagnostic accuracy. This change weights methodological and economic factors heavily, but probably under-values the importance of diagnostic sensitivity.

Recently, a new generation of AGA tests has been developed (34-37). Schwertz et al. (38) demonstrated that an immunoassay based on deamidated synthetic gliadin peptides (DGP) bound to nitrocellulose filters were recognized by sera of CD patients. The recognition of the epitopes containing the sequence QPEQPFP showed high specificity for CD. These data were subsequently confirmed by Sugai et al. (39). A clinical study by Tonutti et al. (40) involving a large group of children with $\mathrm{CD}$, some of whom were anti-tTG negative, showed that anti-DGP antibodies have very high sensitivity and specificity.

Anti-actin IgA antibodies (AAA) are other antibodies that can be found in patients with CD. Recent studies suggest that the detection of AAA can be useful in diagnosing and monitoring $\mathrm{CD}$ because the antibody concentration is related to the degree of intestinal damage (41-44). Indeed, AAA are detectable mainly in CD patients with Marsh 3 lesions and their presence can be considered a marker of intestinal atrophy. However, more recent studies have shown that antitTG IgA concentrations also correlate with histopathological findings in adult and pediatric CD patients (45-51). Subsequently, Hill and Holmes (52) have shown that a ratio $>10$ to the anti-tTG level and the cut-off value is a reliable marker for the presence of Marsh $\geq 2$ lesions.

Taken together, eight different assays (considering both the $\operatorname{IgA}$ and the $\operatorname{IgG}$ isotype) are currently available to diagnose and monitor $\mathrm{CD}$, each one of them with its own characteristics of sensitivity and specificity and each giving different results in adult and pediatric patients (53). Should we then use all these tests? Are some of them just redundant, not providing significant additional information to other tests?

The aim of this study was to evaluate the clinical accuracy of anti-tTG, AGA, anti-DGP, EMA and AAA, both individually and in different combinations in a wide cohort of pediatric patients aged $<6$ years, in order to recommend a panel of tests providing the best efficiency for diagnosing CD.

\section{Patients and methods}

A total of 150 sera were studied: 95 were from consecutive patients with a new diagnosis of $\mathrm{CD}$ made according to the criteria of the European Society of Pediatric Gastroenterology and Nutrition (54). All CD patients were aged $<6$ years (range $1-5.5$ years, median 4.1; 31 males and 64 females). The control group (age range 1-6 years, median 4; 22 males and 33 females) included 32 patients affected by respiratory diseases (allergic asthma and rhinitis) and 23 patients affected by digestive disease: lactose intolerance $(n=4)$, cow milk protein allergy $(n=9)$, Crohn's disease $(n=5)$, indeterminate colitis $(n=2)$ and autoimmune hepatitis $(n=3)$. All patients were referred in the years 2004-2009 to the Immunopathology and
Allergy Department of Palermo "Buccheri La Ferla" Hospital or to the Gastroenterology Department of Palermo "Di Cristina" Children's Hospital. Sera were frozen at $-80^{\circ} \mathrm{C}$ and thawed only once before the serological assays were performed.

Parents of all the children gave consent for the serological investigations performed in this study.

Anti-tTG IgA/IgG and AGA IgG/IgA antibodies were detected with the EliA ImmunoCAP system (Phadia Uppsala, Sweden). The EMA IgA test was conducted by the indirect immunofluorescence method on cryostatic sections of monkey esophagus (INOVA) at a starting dilution of 1:5, which was considered the threshold for positivity.

Anti-DGP IgA and IgG were assayed with a commercial enzyme immunoassay (ELISA) method using synthetic deamidated gliadin peptides containing the antigenic sequence PEQ (Quanta-Lite Gliadin IgA II and IgG II, INOVA, San Diego, CA, USA).

Tests for IgA AAA were performed using a commercial ELISA method (F-Actin Smooth Muscle, INOVA) using an anti-human IgA conjugate as previously described (44). Assays were performed in accordance with the manufacturer's instructions. All sera were tested also for total IgA by nephelometry (BNII Siemens Healthcare, Munich, Germany).

\section{Intestinal biopsy}

At least three biopsy specimens of the second part of the duodenum were obtained and prepared as previously described (6). Specimens were embedded in paraffin and slides were stained with hematoxylin and eosin and graded by conventional histology according to the Marsh classification (55-57). Three CD patients showed Marsh 2 histology, six patients Marsh 3a, 29 patients Marsh 3b and 57 patients Marsh 3c.

\section{Statistical analysis}

The sensitivity and the specificity of each antibody assay were calculated at the cut-off suggested by the manufacturers (seven units for anti-tTG IgA and IgG, seven units for AGA IgA and IgG, 20 units for anti-DGP $\operatorname{IgA}$ and IgG). Cumulative sensitivity and specificity, with $95 \%$ confidence interval (CI) of different test combinations were also calculated. The positive predictive value (PPV) and the negative predictive value (NPV) of all the assays and of their associations were also evaluated. Moreover, the relation between mean levels of anti-tTG IgA, anti-DGP IgA, anti-DGP IgG and AAA IgA antibodies and the Marsh's score was assessed by means of the univariate analysis of variance (ANOVA) test. Finally, the rate of positive results of each antibody was evaluated in relationship to the grade of intestinal atrophy. Statistical analysis was performed using the Medcalc Software Version 10.4.5 for Windows statistical package.

\section{Cost of testing}

The costs of each single assay and of a combination of assays were calculated based on the current Italian price list of laboratory tests.

\section{Results}

\section{Anti-tTG and EMA assays}

Seventy-four of the 95 children with CD (77.9\%) were antitTG IgA positive (range, 8.9-150 units) and EMA IgA positive (range, 1:5-1:1280) (Table 1). The other 21 were 
anti-tTG and EMA negative. Fifty-two of the 74 anti-tTG IgA positive patients were also anti-tTG IgG positive. All 55 control patients were negative for anti-tTG IgA and IgG. Anti-tTG IgA antibodies and the Marsh score of intestinal atrophy were significantly correlated (F-ratio 3.460; $p=0.02$ ). Mean values and standard deviations of anti-tTG IgA antibodies in the Marsh groups are shown in Table 2.

As regards the correlation between anti-tTG IgA antibody assay and the severity of intestinal damage, 29 of the Marsh $3 \mathrm{c}$ patients (50.9\%), 10 of the Marsh 3b patients (34.5\%), one of the Marsh 3a patients (16.7\%) and none of the Marsh two patients had IgA anti-tTG $\geq 10 \times$ the cut-off. Overall, 40/92 Marsh 3 patients were strongly positive for IgA antitTG $(43.5 \%, 95 \% \mathrm{CI}=33.8-53.2)$.

\section{AGA and anti-DGP assays}

Forty-three of 95 (45.3\%) CD patients were AGA IgA positive, 48/95 (50.5\%) were AGA IgG positive, $43 / 95$ (45.3\%) were positive for anti-DGP IgA and 57/95 (60\%) for antiDGP IgG (Table 1). In the control group, 2/55 patients (3.6\%) were positive for AGA IgA and 14/55 (25.4\%) were positive for AGA IgG. No false-positive results were observed for anti-DGP IgA and IgG. Anti-DGP IgA and IgG antibodies and the Marsh score of intestinal atrophy were significantly correlated (F-ratio 3.821; $\mathrm{p}=0.013$ and 3.090; $\mathrm{p}=0.031$, respectively). Mean units and standard deviations of anti-DGP $\operatorname{IgA}$ and of anti-DGP $\operatorname{IgG}$ antibodies in the Marsh groups are shown in Table 2.

As regards the correlation between anti-DGP positivity and the severity of intestinal damage, 42/92 Marsh 3 patients were positive for anti-DPG $\operatorname{IgA}(45.7 \%, 95 \%$ $\mathrm{CI}=35.9-56.4)$ and $56 / 92$ for anti-DPG $\mathrm{IgG}(60.9 \%, 95 \%$ $\mathrm{CI}=51.3-70.4)$.

\section{AAA assay}

IgA AAA were positive in 74 of the 95 (77.9\%) untreated CD patients and 21 were negative (Table 1). Among the 32 control patients affected by respiratory diseases, only one was positive for AAA, whereas in the group with intestinal diseases, seven of 23 patients were positive. There was no significant correlation between AAA levels and the Marsh score (F-ratio 1.801; $\mathrm{p}=0.153$ ). Mean units and standard deviations of AAA in the Marsh groups are shown in Table 2. Forty-nine of the Marsh 3c patients (85.9\%), 22 of the Marsh 3b (75.9\%), three of the Marsh 3a (50\%) and none of the Marsh 2 patients were AAA positive. Overall, 74/92 Marsh 3 patients were AAA positive $(80.4 \%, 95 \%$ $\mathrm{CI}=72.7-88.2$ ).

\section{Total IgA assay}

None of the sera showed IgA deficiency (total serum IgA $<0.5 \mathrm{mg} / \mathrm{L})$.

\section{Diagnostic accuracy of combined tests}

Seventy-six of 95 (80\%) CD patients were positive for antiDGP IgA and/or anti-tTG IgA. Eighty of 95 (84.2\%) CD 
Table 2 Mean values and standard deviation (SD) of anti-tTG IgA, anti-DGP IgA and IgG, and AAA antibody concentrations in relation to the Marsh score of intestinal atrophy.

\begin{tabular}{lllllc}
\hline $\begin{array}{l}\text { Marsh } \\
\text { score }\end{array}$ & no. & $\begin{array}{l}\text { tTG-IgA } \\
\text { Mean units } \pm \text { SD }\end{array}$ & $\begin{array}{l}\text { DGP-IgA } \\
\text { Mean units } \pm \text { SD }\end{array}$ & $\begin{array}{l}\text { DGP-IgG } \\
\text { Mean units } \pm \text { SD }\end{array}$ & $\begin{array}{l}\text { AAA-IgA } \\
\text { Mean units } \pm S D\end{array}$ \\
\hline 2 & 3 & $13.0 \pm 2.6$ & $12.6 \pm 1.7$ & $15.3 \pm 0.9$ & $3.6 \pm 0.5$ \\
$3 \mathrm{a}$ & 6 & $41.5 \pm 31.3$ & $13.8 \pm 2.5$ & $31.1 \pm 24.1$ & $16.1 \pm 12.9$ \\
3b & 29 & $61.5 \pm 41.9$ & $19.6 \pm 16.8$ & $31.5 \pm 26.8$ & $20.7 \pm 17.1$ \\
3c & 57 & $80.3 \pm 50.8$ & $37.4 \pm 33.1$ & $49.2 \pm 34.7$ & $26.2 \pm 22.0$ \\
\hline
\end{tabular}

tTG, anti-tissue transglutaminase antibodies; DGP, anti-deamidated gliadin antibodies; AAA, anti-actin antibodies.

patients were positive for DGP IgG and/or tTG IgA. Seventy-eight of 95 (82.1\%) CD patients and 14/55 (25.4\%) controls were positive for AGA IgG and/or tTG IgA. Seventy-four patients and two controls were positive for AGA IgA and/or tTG IgA. Seventy-four patients and nine controls were positive for AGA IgA and/or AAA. Eighty patients and nine controls were positive for AGA IgG and/or AAA. Eighty-four patients and eight controls were positive for AAA and/or tTG IgA. We did not consider the accuracy value of the combination of EMA IgA with anti-tTG IgG because all sera that were anti-tTG IgG and EMA positive were also anti-tTG IgA positive. None of the control patients were EMA IgA and anti-tTG IgA and/or IgG positive. The diagnostic performances of AGA, DGP and tTG combined tests are summarized in Table 3. Association of anti-tTG IgA with anti-DGP IgG proved to be the best test combination, with a cumulative sensitivity of $84.2 \%(95 \% \mathrm{CI}=77.1-91.4)$ and a specificity of $100 \%$. The PPV of this combination is $100 \%$ and the NPV is $78.6 \%$ (95\% CI $=70.5-86.8)$.

\section{Cost of testing}

Table 4 presents the costs of each single test and of test combinations.

If only the anti-tTG IgA assay is used as a screening test, the cost per patient is $€ 15.51$.

Given that 74 out of $95 \mathrm{CD}$ patients had positive anti-tTG IgA test results, the cost for each CD diagnosis in the studied population is $€ 18.63$. However, if we use this single test approach, the additional cost of testing total serum IgA, $€ 5.03$, must be added, since this step is necessary for identifying subjects with IgA deficit. This brings the total cost per patient to $€ 19.54$ and per diagnosis to $€ 25$.08.

If, in the screening profile the anti-DGP IgG test is combined with the anti-tTG IgA test, the total cost is $€ 25.92$ per patient, with six additional patients diagnosed. Using this approach, the total cost for each diagnosis is $€ 30.78$ (an 18\% increase), with no need to test for total serum IgA because IgA-deficient patients would be identified by the DGP IgG test.

\section{Discussion}

In the last two decades, the use of anti-tTG antibodies as more accurate markers for $\mathrm{CD}$ has largely replaced AGA testing for CD diagnosis (58). Although AGA testing is not recommended by the NASPHAGAN guidelines (30), it could still be considered useful in pediatric patients who test negative for anti-tTG or in IgA-deficient patients $(9,25,59,60)$ because the anti-tTG assay has insufficient sensitivity in very young children.

In recent years it has been shown that the new anti-DGP ELISA tests using deamidated gliadin peptides as antigen have a high sensitivity and a specificity comparable to those of anti-tTG and EMA and higher than AGA $(25,38-40)$.

In this study we evaluated the diagnostic accuracy of different combinations of several assays in CD diagnosis in a large series of very young pediatric patients, with the objective of determining the test, or combination of tests, best able to ensure the greatest diagnostic efficacy.

We confirmed that the anti-DGP tests have higher specificity (IgA 100\%, IgG 100\%) than AGA tests (IgA 96.4\%, IgG 74.6\%), as well as higher sensitivity (DGP IgA $45.3 \%$, $\operatorname{IgG} 60.0 \%$ vs. AGA (IgA 45.3\%, IgG 50.5\%). In this respect, it is noteworthy that none of the $\mathrm{CD}$ subjects that were negative for DGP IgG tested positive for AGA (either $\operatorname{IgA}$ or $\operatorname{IgG})$. These findings confirm the widespread opinion that the AGA test has limited usefulness for the diagnosis of CD. Our data also showed that in children, EMA and antitTG IgA have an equal diagnostic accuracy, but the anti-tTG IgA test should be preferred because it is fully automatized and it is not prone to subjective interpretation.

The most relevant aspect highlighted by our study is that the combination of anti-tTG IgA with anti-DGP IgG increases the accuracy for $\mathrm{CD}$ diagnosis in very young children. Indeed, by combining anti-tTG IgA with anti-DGP IgG, the clinical sensitivity increased from $77.9 \%$ of the anti-tTG IgA alone to $84.2 \%$, maintaining, at the same time, a very high specificity (100\%). The PPV and NPV (100\% and 78.6\%, respectively) also indicate that anti-tTG IgA plus anti-DGP $\mathrm{IgG}$ is the best test combination. Our findings are important because they confirm in a pediatric population the results obtained by Volta et al. (61) in adult CD patients. Furthermore, although our patient series did not include subjects with IgA deficiency, a high accuracy of the anti-DGP IgG assay has been reported in IgA-deficient CD children (62, 63), showing that this combination of diagnostic tests may enable accurate recognition even of CD patients with IgA deficiency. Even if the highest sensitivity (88.4\%) and NPV $(81.1 \%)$ were observed by the association of anti-tTG IgA and AAA, the specificity of these two combined assays fell to $85.5 \%$. These findings suggest that the AAA test has limited usefulness for the diagnosis of $\mathrm{CD}$ and are in agreement 
Table 4 Costs of each single test and of test association for the diagnosis of celiac disease, according to the Italian list of laboratory tests.

\begin{tabular}{lc}
\hline Assays & Euro $(€)$ \\
\hline tTG IgA or IgG & 14.51 \\
EMA & 14.51 \\
DGP IgA or IgG & 11.41 \\
AGA IgA or IgG & 11.41 \\
AAA & 14.51 \\
Total IgA & 5.03 \\
tTG IgA + total IgA & 19.54 \\
tTG IgA + DGP IgG & 25.92 \\
tTG IgA + AAA & 29.02 \\
DGP IgG + AAA & 25.92 \\
tTG IgA + DGP IgA + AAA & 40.43 \\
\hline
\end{tabular}

EMA, anti-endomysium antibodies; tTG, anti-tissue transglutaminase antibodies; DGP, anti-deamidated gliadin antibodies; AGA, anti-gliadin antibodies; AAA, anti-actin antibodies.

with those reported by previous studies that showed that the AAA assay cannot replace EMA and anti-tTG in the diagnostic algorithm of CD $(43,44,59)$. We confirm, however, that AAA positivity is associated with severe intestinal damage, as reported by other researchers (41-44). Therefore, in the follow-up of pediatric patients with $\mathrm{CD}$ (i.e., monitoring the adherence to gluten-free diet), the AAA test may provide important information about mucosal status without the use of an invasive procedure (64-68). Regarding the possible use of elevated anti-tTG IgA levels as markers of severe histological damage, we confirm the data obtained by Donaldson et al. $(48,49)$ and Hill and Holmes $(52)$, showing that all patients with elevated anti-tTG $\operatorname{IgA}$ concentrations had Marsh 3 intestinal atrophy.

In conclusion, our data suggest that the best serological approach to diagnosing $\mathrm{CD}$ in pediatric patients is based on combining anti-tTG IgA and anti-DGP IgG assays, with only a moderate increase of screening costs. These tests may be performed either simultaneously or sequentially. Simultaneous testing would probably be more straightforward and guarantee a faster turn-around time. A sequential approach, based on a reflex strategy (i.e., testing for anti-DGP IgG only in patients who test negative for anti-tTG $\operatorname{IgA}$ ) could contain costs and be equally effective if supported by reflex testing automation. The use of AAA could be limited to support the diagnosis of $\mathrm{CD}$ when histological findings are controversial or to evaluate the adherence to diet of CD patients $(44,69)$. However, more data are warranted before their use in these particular situations could be recommended.

\section{Conflict of interest statement}

Authors' conflict of interest disclosure: The authors declare that this study was not financially supported by any pharmaceutical organization or industry.

Research funding: None declared.

Employment or leadership: None declared.

Honorarium: None declared. 


\section{References}

1. Carlsson AK, Axelsson IE, Borulf SK, Bredberg AC, Ivarsson SA. Serological screening for celiac disease in healthy 2.5 -yearold children in Sweden. Pediatric 2001;107:42-5.

2. Not T, Horvath K, Hill I, Partanen J, Hammed A, Magazzu G, et al. Celiac disease risk in the USA: high prevalence of antiendomysium antibodies in healthy blood donors. Scand J Gastroenterol 1998;33:494-8.

3. Catassi C, Ratsch IM, Fabiani E, Rossini M, Bordicchia F, Candela F. Celiac disease in the year 2000: exploring the iceberg. Lancet 1994;343:200-3.

4. Ferreira M, Davies SL, Butler M, Scott D, Clark M, Kumar P. Endomysial antibody: is it the best screening test for coeliac disease? Gut 1992;33:1633-7.

5. Dieterich W, Laag E, Schöpper H, Volta U, Ferguson A, Gillett $\mathrm{H}$, et al. Autoantibodies to tissue transglutaminase as predictors of celiac disease. Gastroenterology 1998;115:1317-21.

6. Carroccio A, Vitale G, Di Prima L, Chifari N, Napoli S, La Russa C, et al. Comparison of anti-transglutaminase ELISAs and anti-endomysial antibody assay in the diagnosis of celiac disease: a prospective study. Clin Chem 2002;48:1546-50.

7. Reeves GE, Squance ML, Duggan AE, Murugasu RR, Wilson RJ, Wong RC, et al. Diagnostic accuracy of coeliac serological tests: a prospective study. Eur J Gastroenterol Hepatol 2006;18: 493-501.

8. Basso D, Guariso G, Plebani M. Serologic testing for celiac disease. Clin Chem 2002;48:2082-3.

9. Hoffenberg EJ, MacKenzie T, Barriga KJ, Eisenbarth GS, Bao F, Haas JE, et al. A prospective study of the incidence of childhood celiac disease. J Pediatr 2003;143:308-14.

10. Simell S, Kupila A, Hoppu S, Hekkala A, Simell T, Ståhlberg MR, et al. Natural history of transglutaminase autoantibodies and mucosal changes in children carrying HLA-conferred celiac disease susceptibility. Scand J Gastroenterol 2005;40:1182-91.

11. Panetta F, Torre G, Colistro F, Ferretti F, Daniele A, Diamanti A. Clinical accuracy of anti-tissue transglutaminase as screening test for celiac disease under 2 years. Acta Paediatr 2011; 100:728-31.

12. Vitoria JC, Arrieta A, Arranz C, Ayesta A, Sojo A, Maruri N, et al. Antibodies to gliadin, endomysium, and tissue transglutaminase for the diagnosis of celiac disease. J Pediatr Gastroenterol Nutr 1999;29:571-4.

13. Bonamico M, Tiberti C, Picarelli A, Mariani P, Rossi D, Cipolletta E, et al. Radioimmunoassay to detect antitransglutaminase autoantibodies is the most sensitive and specific screening method for celiac disease. Am J Gastroenterol 2001; 96:1536-40.

14. Baldas V, Tommasini A, Trevisiol C, Berti I, Fasano A, Sblattero D, et al. Development of a novel rapid non-invasive screening test for coeliac disease. Gut 2000;47:628-31.

15. Stern M. Comparative evaluation of serologic tests for celiac disease: a European initiative toward standardization. J Pediatr Gastroenterol Nutr 2000;31:513-9.

16. Sulkanen S, Halttunen T, Laurilla K, Kolho K. Tissue transglutaminase autoantibody enzyme-linked immunosorbent assay in detecting celiac disease. Gastroenterology 1998;115:1322-8.

17. Mankai A, Sakly W, Landolsi H, Gueddah L, Sriha B, Ayadi A, et al. Tissue transglutaminase antibodies in celiac disease, comparison of an enzyme linked immunosorbent assay and a dot blot assay. Pathol Biol 2005;53:204-9.

18. Lagerqvist C, Dahlbom I, Hansson T, Jidell E, Juto P, Olcén P, et al. Anti gliadin immunoglobulin A best in finding celiac disease in children younger than 18 months of age. J Pediatr Gastroenterol Nutr 2008;47:428-35.

19. Van Meensel B, Hiele M, Hoffman I, Vermeire S, Rutgeerts P, Geboes K, et al. Diagnostic accuracy of ten second-generation (human) tissue transglutaminase antibody assays in celiac disease. Clin Chem 2004;50:2125-35.

20. Burgin-Wolff A, Gaze H, Hadziselimovic F, Huber H, Lentze MJ, Nusslé D, et al. Antigliadin and antiendomysium antibody determination for coeliac disease. Arch Dis Child 1991;66: 941-7.

21. Bode S, Weile B, Krasilnikoff PA, Gudmand-Hoyer E. The diagnostic value of the gliadin antibody test in celiac disease in children: a prospective study. J Pediatr Gastroenterol Nutr 1993;17:260-4.

22. Carroccio A, Iacono G, Montalto G, Cavataio F, Soresi M, Kazmierska I, et al. Immunologic and absorptive tests in celiac disease: can they replace intestinal biopsies? Scand J Gastroenterol 1993;28:673-6.

23. Berger R, Schmidt G. Evaluation of six anti-gliadin antibody assays. J Immunol Methods 1996;191:77-86.

24. Rostom A, Dubé C, Cranney A, Saloojee N, Sy R, Garritty C, et al. The diagnostic accuracy of serological test for celiac disease: a systematic review. Gastroenterology 2005;128:S38-46.

25. Laass MW, Koch T, Lösel A, Conrad K, Henker J. Longitudinal follow-up examination of antigliadin antibody positive children and adults. Eur J Gastroenterol Hepatol 2006;18:503-6.

26. Burgin-Wolff A, Berger R, Gaze H, Huber H, Lentze MJ, Nussle D. IgG, IgA and IgE gliadin antibody determinations as screening test for untreated coeliac disease in children, a multicentre study. Eur J Pediatr 1989;148:496-502.

27. De Lecea A, Ribes-Koninckx C, Polanco I, Calvete JF. Serological screening (antigliadin and antiendomysium antibodies) for nonovert coeliac disease in children of short stature. Acta Paediatr Suppl 1996;412:54-5.

28. Lerner A, Kumar V, Iancu TC. Immunological diagnosis of childhood coeliac disease: comparison between antigliadin, antireticulin and antiendomysial antibodies. Clin Exp Immunol 1994;95:78-82.

29. Sacchetti L, Ferrajolo A, Salerno G, Esposito P, Lofrano MM, Oriani G, et al. Diagnostic value of various serum antibodies detected by diverse methods in childhood celiac disease. Clin Chem 1996;42:1838-42.

30. Hill ID, Dirks MH, Liptak GS, Colletti RB, Fasano A. Guideline for the diagnosis and treatment of celiac disease in children: recommendations of the North American Society for Pediatric Gastroenterology, Hepatology and Nutrition. J Pediatr Gastroenterol Nutr 2005;40:1-19.

31. Bottaro G, Volta U, Spina M, Rotolo N, Sciacca A, Musumeci S. Antibody pattern in childhood celiac disease. J Pediatr Gastroenterol Nutr 1997;24:559-62.

32. Savilahti E, Viander M, Perkkiö M, Vainio E, Kalimo K, Reunala T. IgA antigliadin antibodies: a marker of mucosa damage in childhood coeliac disease. Lancet 1983;12:320-2.

33. Tonutti E, Visentini D, Bizzaro N, Caradonna M, Cerni L, Villalta $\mathrm{D}$, et al. The role of anti-tissue transglutaminase assay for the diagnosis and monitoring of coeliac disease: a FrenchItalian multicentre study. J Clin Pathol 2003;56:389-93.

34. Koning F. Celiac disease: caught between a rock and a hard place. Gastroenterology 2005;129:1294-301.

35. Aleanzi M, Demonte AM, Esper C, Garcilazo S, Waggener M. Celiac disease: antibody recognition against native and selectively deamidated gliadin peptides. Clin Chem 2001;47: 2023-8. 
36. Sjöström H, Lundin KE, Molberg O, Körner R, McAdam SN, Anthonsen D, et al. Identification of a gliadin T-cell epitope in coeliac disease: general importance of gliadin deamidation for intestinal T-cell recognition. Scand J Immunol 1998;48:111-5.

37. Molberg O, Mcadam SN, Körner R, Quarsten H, Kristiansen $\mathrm{C}$, Madsen L, et al. Tissue transglutaminase selectively modifies gliadin peptides that are recognized by gut derived $\mathrm{T}$ cells in celiac disease. Nat Med 1998;4:713-7.

38. Schwertz E, Kahlenberg F, Sack U, Richter T, Stern M, Conrad $\mathrm{K}$, et al. Serologic assay based on gliadin-related nonapeptides as a highly sensitive and specific diagnostic aid in celiac disease. Clin Chem 2004;50:2370-5.

39. Sugai E, Vázquez H, Nachman F, Moreno ML, Mazure R, Smecuol E, et al. Accuracy of testing for antibodies to synthetic gliadin-peptides in celiac disease. Clin Gastroenterol Hepatol 2006; 4:1112-7.

40. Tonutti E, Visentini D, Picierno A, Bizzaro N, Villalta D, Tozzoli R, et al. Diagnostic efficacy of the ELISA test for the detection of deamidated anti-gliadin peptide antibodies in the diagnosis and monitoring of celiac disease. J Clin Lab Anal 2009;23:165-71.

41. Clemente MG, Musu MP, Frau F, Brusco G, Sole G, Corazza $\mathrm{GR}$, et al. Immune reaction against the cytoskeleton in celiac disease. Gut 2000;47:520-6.

42. Clemente MG, Musu MP, Troncone R, Volta U, Congia M, Ciacci $\mathrm{C}$, et al. Enterocyte actin antibody detection: a new diagnostic tool in celiac disease diagnosis: results of a multicenter study. Am J Gastroenterol 2004;99:1551-6.

43. Carroccio A, Brusca I, Iacono G, Di Prima L, Teresi S, Pirrone $\mathrm{G}$, et al. Anti-actin antibodies in celiac disease: correlation with intestinal mucosa damage and comparison of ELISA with the immunofluorescence assay. Clin Chem 2005;51:917-20.

44. Carroccio A, Brusca I, Iacono G, Alessio MG, Sonzogni A, Di Prima L, et al. IgA anti-actin antibodies ELISA in coeliac disease: a multicentre study. Dig Liver Dis 2007;39:818-23.

45. Hoffenberg EJ, Bao F, Eisenbarth GS, Uhlhorn C, Haas JE, Sokol RJ, et al. Transglutaminase antibodies in children with a genetic risk for celiac disease. J Pediatr 2000;137:356-60.

46. Tursi A, Brandimarte G, Giorgetti GM. Prevalence of antitissue transglutaminase antibodies in different degrees of intestinal damage in celiac disease. J Clin Gastroenterol 2003;36:219-21.

47. Jatla M, Bokhari A, Bierly P, Russo P, Verma R. Anthropometric, serologic, and laboratory correlation with villous blunting in pediatric celiac disease: diabetics are different. J Clin Gastroenterol 2009;43:622-6.

48. Donaldson MR, Firth SD, Wimpee H, Leiferman KM, Zone JJ, Horsley W, et al. Correlation of duodenal histology with tissue transglutaminase and endomysial antibody levels in pediatric celiac disease. Clin Gastroenterol Hepatol 2007;5:567-73.

49. Donaldson MR, Book LS, Leiferman KM, Zone JJ, Neuhausen SL. Strongly positive tissue transglutaminase antibodies are associated with Marsh 3 histopathology in adult and pediatric celiac disease. J Clin Gastroenterol 2008;42:256-60.

50. Barker CC, Mitton C, Jevon G, Mock T. Can tissue transglutaminase antibody titers replace small bowel biopsy to diagnose celiac disease in selected pediatric populations? Pediatrics 2005;115:1341-6.

51. Diamanti A, Colistro F, Calce A, Devito R, Ferretti F, Minozzi A, et al. Clinical value of immunoglobulin A antitransglutaminase assay in the diagnosis of celiac disease. Pediatrics 2006;118:1696-700.
52. Hill PG, Holmes KT. Coeliac disease: a biopsy is not always necessary for diagnosis. Alim Pharmacol Ther 2008;27:572-7.

53. Bizzaro N, Tozzoli R, Villalta D, Fabris M, Tonutti E. Cutting edge issues in celiac disease and in gluten intolerance. Clin Rev Allergy Immunol 2010;23. [Epub ahead of print].

54. Revised criteria for diagnosis of coeliac disease. Report of Working Group of European Society of Paediatric Gastroenterology and Nutrition. Arch Dis Child 1990;65:909-11.

55. Marsh MN, Crowe PT. Morphology of the mucosal lesion in gluten sensitivity. Baillière's Clin Gastroenterol 1995;9:273-93.

56. Oberhuber G, Granditsch G, Vogelsang H. The histopathology of celiac disease: time for a standardized report scheme for pathologists. Eur J Gastroenterol Hepatol 1999;11:1185-94.

57. Antonioli DA. Celiac disease: a progress report. Mod Pathol 2003;16:342-6.

58. Lock RJ, Pitcher MC, Unsworth DJ. IgA anti-tissue transglutaminase as diagnostic marker of gluten sensitive enteropathy. J Clin Pathol 1999;52:274-7.

59. Granito A, Muratori P, Cassani F, Pappas G, Muratori L, Agostinelli D, et al. Anti-actin IgA antibodies in severe coeliac disease. Clin Exp Immunol 2004;137:386-92.

60. Lenhardt A, Plebani A, Marchetti F, Gerarduzzi T, Not T, Meini A, et al. Role of human-tissue transglutaminase $\operatorname{IgG}$ and antigliadin IgG antibodies in the diagnosis of coeliac disease in patients with selective immunoglobulin A deficiency. Dig Liver Dis 2004;36:730-4.

61. Volta U, Fabbri A, Parisi C. Deamidated gliadin peptide antibodies as a routine test for celiac disease: a prospective analysis. J Clin Gastroenterol 2010;44:186-90.

62. Villalta D, Alessio MG, Tampoia M, Tonutti E, Brusca I, Bagnasco $\mathrm{M}$, et al. Testing for IgG class antibodies in celiac disease patients with selective IgA deficiency. A comparison of the diagnostic accuracy of $9 \mathrm{IgG}$ anti-tissue transglutaminase, $1 \mathrm{IgG}$ anti-gliadin and $1 \mathrm{IgG}$ anti-deaminated gliadin peptide antibody assays. Clin Chim Acta 2007;382:95-9.

63. Villalta D, Tonutti E, Prause C, Koletzko S, Uhlig HH, Vermeersch $\mathrm{P}$, et al. IgG antibodies against deamidated gliadin peptides for diagnosis of celiac disease in patients with IgA deficiency. Clin Chem 2010;56:464-8.

64. Guandalini S, Gupta P. Do you still need a biopsy to diagnose celiac disease? Curr Gastroenterol Rep 2001;3:385-91.

65. Scoglio R, Di Pasquale G, Pagano G, Lucanto MC, Magazzù G, Sferlazzas C. Is intestinal biopsy always needed for diagnosis of celiac disease? Am J Gastroenterol 2003;98:1325-31.

66. Murdock AM, Johnston SD. Diagnostic criteria for coeliac disease: time for change? Eur J Gastroenterol Hepatol 2005; 17:41-3.

67. Barker CC, Mitton C, Jevon G, Mock T. Can tissue transglutaminase antibody titers replace small-bowel biopsy to diagnose celiac disease in select pediatric populations? Pediatrics 2005;115:1341-6.

68. Sugai E, Moreno ML, Hwang HJ, Cabanne A, Crivelli A, Nachman F, et al. Celiac disease serology in patients with different pretest probabilities: is biopsy avoidable? World J Gastroenterol 2010;16:3144-52.

69. Bazzigaluppi E, Parma B, Tronconi GM, Corsin P, Albarello L, Mora S, et al. IgA anti-Actin antibodies in children with celiac disease: comparison of immunofluorescence with Elisa assay in predicting severe intestinal damage. It J Pediatrics 2010;36:25. 